Revista de Economia Política, vol. 29, $n^{\circ} 1$ (113), pp. 24-42, janeiro-março/2009

\title{
Déficits gêmeos e poupança nacional: abordagem teórica
}

\author{
MARCO FLÁVIO DA CUNHA RESENDE*
}

Budget deficit and national savings: theoretical approach. A consensus has not yet emerged about the relationship between budget deficit, external deficit and national saving. According to mainstream economic literature the budget deficit can cause an insufficiency of national saving for a given investment rate. In this case, the investment rate will not be reduced if foreign saving is absorbed, causing an external deficit. In general, the mechanisms through which budget deficits could cause current account deficits are not highlighted in the works about this theme. We arrive at the conclusion that there is not a systematic relationship between budget deficit, current account deficit and national saving and that when it happens it can be processed only through changes in the real exchange rate.

Keywords: Budget deficit; current account; national saving; real exchange rate. JEL Classification : E21; E22; E62; F30; F41.

\section{INTRODUÇÃO}

Um consenso ainda não foi alcançado na literatura econômica sobre a relação entre déficit público, déficit em transações correntes e poupança nacional. É comum o argumento de que o déficit público resulta em déficit em transações correntes do balanço de pagamentos (déficits gêmeos). Porém, os mecanismos através dos quais o déficit público causa um déficit externo não são, em geral, demonstrados nos estudos sobre o tema.

\footnotetext{
* Do Centro de Desenvolvimento e Planejamento Regional da Universidade Federal de Minas Gerais - CEDEPLAR-UFMG; resende@cedeplar.ufmg.br O autor agradece a Adriana M. Amado, Frederico G. Jayme Jr., Flavius M. L. Vasconcelos, Cândido L. Fernandes e a dois pareceristas anônimos pelos comentários referentes a uma versão preliminar deste estudo, eximindo-os de responsabilidade pelos erros e omissões porventura remanescentes. Submetido: Maio 2005; Aprovado: Outubro 2006.
} 
O objetivo deste artigo é investigar a validade da relação entre déficit púbico, deterioração da poupança nacional e déficit em conta corrente. Busca-se, ainda, identificar os mecanismos através dos quais estas variáveis poderiam estar relacionadas.

Além desta introdução, o artigo conta com outras duas seções. Na segunda seção duas são apresentados argumentos pró e contra a tese dos déficits gêmeos (déficit público e externo) e os mecanismos através dos quais estes déficits poderiam estar vinculados. A terceira seção destina-se às conclusões do trabalho.

\section{DÉFICIT PÚBLICO, TAXA DE CÂMBIO REAL E DÉFICIT EM CONTA CORRENTE}

O estudo teórico e empírico da relação entre déficit público e saldo em conta corrente do balanço de pagamentos tem sido objeto de controvérsia. Em geral, estes estudos baseiam-se na seguinte identidade macroeconômica ${ }^{1}$ :

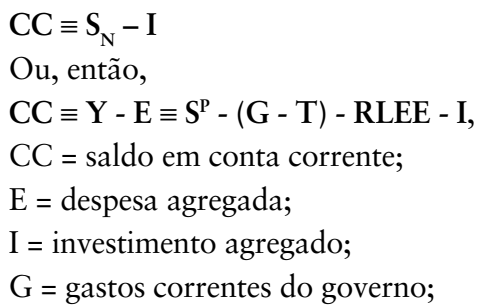

$\mathrm{Y}=$ renda nacional;

$\mathrm{S}^{\mathrm{p}}=$ poupança privada agregada;

$\mathrm{T}=$ receitas correntes do governo;

$\mathrm{T}-\mathrm{G}=$ poupança pública;

$S_{N}=$ poupança nacional $=S^{P}+(T-G)-R L E E ; \quad R L E E=$ renda líquida enviada ao exterior

É comum o argumento de que o déficit público resulta em déficit em transações correntes (déficits gêmeos). Tal argumento baseia-se na identidade macroeconômica supracitada ${ }^{2}$. Porém, as identidades das Contas Nacionais (CN) têm uma natureza contábil: as variações de estoque são contempladas, desejadas ou não. As $\mathrm{CN}$ representam uma situação de "equilíbrio macroeconômico ex-post". Portanto, a identidade supracitada "não é uma teoria econômica ou uma regularidade empírica, mas uma identidade contábil sobre a qual não pode haver nenhum debate" (Feldstein, 1992: 4). Ainda, “(...) olhar para as identidades nunca pode ser a análise completa. Devemos perguntar como a identidade contábil é traduzida em incentivos que afetam o comportamento individual" (Krugman, 1992:5) ${ }^{3}$.

"O vínculo entre desequilíbrios orçamentários e desequilíbrios comerciais é

\footnotetext{
${ }^{1}$ Ver, por exemplo, Baharumshah et al. (2005), Vamvoukas (1999), Krugman (1992), Feldstein (1992), Rosensweig e Tallman (1993), Oskooee (1995), Giambiagi \& Amadeo (1990), Amadeo (1995), Resende (1995).

${ }^{2}$ Ver, por exemplo, Resende (1995) e Vamvoukas (1999).

3 “A contabilidade nacional (...) não passa de um aglomerado de tautologias (...) As explicações da inflação e do déficit de transações correntes pelo déficit público, acima apresentadas, pecam exatamente pela extrema pobreza das hipóteses de comportamento (...) as relações entre causa e efeito são muito
} 
muito fraco" (Krugman, 1992: 4). Em primeiro lugar, o desequilíbrio fiscal pode apenas deslocar gastos privados (crowding out) e/ou estimular a poupança privada (Equivalência Ricardiana), sem afetar, portanto, o CC. Em segundo lugar, não estão claros os mecanismos através dos quais um excesso da absorção doméstica sobre a produção nacional deterioraria o CC. Segundo Krugman (1992), mudanças no CC dependem de alterações na distribuição dos gastos mundiais, sendo que tais alterações dependem de mudanças na taxa de câmbio real ${ }^{4}$.

Ou seja, ele argumenta que para alguns autores, como McKinnon (1984), hiatos de poupança-investimento são diretamente refletidos na balança comercial, sem necessidade de alteração dos preços relativos, quando há mobilidade de capitais. Porém, este argumento confunde se uma mudança na taxa de poupança será refletida em uma mudança na distribuição dos gastos mundiais com outra questão, a saber, se uma mudança nessa distribuição requer uma mudança de preços relativos (Krugman, 1992: 15). A última questão é uma questão sobre o mercado de bens, e não sobre o mercado de capitais. Krugman (1992: 14) demonstra que a correção do desequilíbrio no CC num contexto de pleno emprego só é viável mediante mudanças na taxa de câmbio real. ${ }^{5}$

É comum o argumento de que o desequilíbrio das contas públicas implica excesso do investimento sobre a poupança nacional. Isto resulta em absorção de poupança externa (CC deficitário), necessária para compensar a insuficiência de poupança nacional. Ou seja, o investimento corresponde ao aumento do estoque de capital físico da economia (formação bruta de capital fixo mais variação de estoques; Simonsen \& Cysne, 1995: 151) e, em equilíbrio macroeconômico (ex post), é contabilmente igual à soma das poupanças nacional e externa (Feijó et al., 2001: 8). Assim, a poupança nacional é a renda nacional não consumida e está

mais complexas do que o simples instrumental da contabilidade nacional pode revelar." Simionsen \& Cysne (1995: 165).

${ }^{4}$ Sobre o tema dos déficits gêmeos, Krugman (1992: 24) argumenta que há uma conclusão definitiva e uma probabilidade. A redução de desequilíbrios externos requer depreciação do câmbio real nos países deficitários e apreciação do câmbio real nos países superavitários, e isto é definitivo. Porém, a contribuição dos desequilíbrios fiscais para ampliar os desequilíbrios externos seria apenas uma probabilidade. A esse respeito, Pastore \& Pinotti (1995: 140) consideram que "estabelecer se as flutuações do câmbio real são menos importantes do que as variações do excesso de absorção sobre o produto na determinação da magnitude dos saldos comerciais, no entanto, é uma questão empírica, com as evidências favorecendo a importância relativa da taxa cambial". Ainda, "Investigações empíricas recentes sobre a relação entre os déficits orçamentário e comercial geraram resultados dúbios" Vamvoukas (1999: 1093). "Um grande número recente de artigos examina a relação entre déficits orçamentário e comercial. Cada artigo contribui com importantes insights, mas nenhum consenso ainda foi alcançado”. Rosensweig \& Tallman (1993: 580).

\footnotetext{
${ }^{5} \mathrm{O}$ autor demonstra que apenas em uma situação teórica, que não prevalece na prática, seria possível corrigir o desequilíbrio em conta corrente de uma economia em pleno emprego apenas através da redistribuição dos gastos mundiais. Porém, o modelo de Krugman (1992) pode ser refinado supondo dois setores: o de bens comerciáveis e o de não comerciáveis. Nesse caso, a redistribuição dos gastos mundiais, por maior que seja, não corrige de tal desequilíbrio num contexto de pleno emprego, fazendo-se necessária uma mudança de preços relativos para o alcance desse objetivo.
} 
associada à produção de capital. Se o déficit público implica aumento do consumo para um dado nível de renda, argumenta-se que haverá redução da taxa de poupança nacional, isto é, insuficiência de poupança nacional para um dado nível de investimento (Resende, 1995). O excesso do investimento agregado em relação à poupança nacional estaria associado a um déficit em conta corrente (absorção de poupança externa). Todavia, os mecanismos através dos quais este processo se manifesta não são claros.

Tavares et alli (1982: 35) argumentam que tal processo não é concretamente possível visto que em certo momento do tempo o estoque de capital da economia está dado. Deste modo, o aumento da absorção doméstica não pode transformar bens de capital destinados à produção de capital em bens de capital destinados à produção de bens de consumo, e vice-versa ${ }^{6}$. Neste caso, o déficit público não reduz a disponibilidade interna de máquinas e equipamentos requeridos para o investimento e, então, seriam falaciosas as relações entre déficit público e insuficiência de poupança nacional e entre déficit público e déficit externo.

Todavia, o argumento de Tavares et al. (1982) só é válido para economias fechadas. Se alterações na absorção doméstica vierem acompanhadas de mudanças dos preços relativos haverá mudanças na oferta de bens de investimento, alterando a poupança nacional, em economias abertas. Através da depreciação (apreciação) da taxa de câmbio real a poupança nacional pode ser ampliada (reduzida) ${ }^{7}$.

Há dois efeitos distintos relacionados à mudança da taxa de câmbio real: o aumento relativo dos preços dos bens comerciáveis (BC) estimula a substituição do consumo em direção aos não-comerciáveis (BNC), ao mesmo tempo em que estimula o aumento da produção daqueles. Segundo Pastore \& Pinotti (1995: 141), com a desvalorização da taxa de câmbio real, a receita marginal eleva-se em relação ao custo marginal no setor de BC, visto que BNC são insumos para a produção de BC. Neste caso, uma nova otimização será realizada elevando a utilização de BNC, que serão empregados até o ponto no qual a receita marginal volte a se igualar ao custo marginal, elevando a produção de BC.

Resultado semelhante também é obtido quando se trabalha com um modelo de fixação de preços segundo a regra de mark-up, e onde a economia não opera necessariamente a pleno emprego ${ }^{8}$. O aumento do preço no setor de $\mathrm{BNC}$ em relação ao setor de $\mathrm{BC}$ pode eliminar produtores de $\mathrm{BC}$ menos eficientes por meio do esmagamento de suas margens de lucro decorrente do aumento de custos de pro-

\footnotetext{
6 “A abstinência do trabalhador (...) não pode converter-se em poupança efetiva (...) Isto pela simples razão de que, da banana ao feijão preto, do rádio de pilha ao tevê em cores, nenhum desses produtos postos à margem do consumo pode transmutar-se, num passe de mágica, no cimento, no aço ou no projeto de engenharia que irão constituir a base real do investimento.” Tavares et al. (1982: 35).

7 “não há nenhum canal direto pelo qual a relação poupança-investimento é refletida de alguma maneira no saldo comercial sem afetar a taxa de câmbio real.” Krugman (1992: 24).

${ }^{8}$ Sobre o modelo de mark-up ver, por exemplo, Kandir (1989), Pereira (1999).
} 
dução - aumento de preços de BNC. Do mesmo modo, a queda do preço relativo de BNC viabiliza a entrada de produtores menos eficientes no setor de BC.

$\mathrm{O}$ aumento dos preços dos $\mathrm{BC}$ em relação aos preços dos BNC resulta, então, em aumento do saldo comercial. A elevação das exportações líquidas corresponde contabilmente à ampliação da poupança nacional ${ }^{9}$. Portanto, máquinas que produzem bens de consumo não podem se metamorfosear em máquinas produtoras de bens de investimento, porém, os bens de consumo exportados geram divisas externas para importar bens de capital.

O aumento da absorção doméstica acima de uma dada taxa de crescimento do produto potencial, quando acompanhado de apreciação da taxa de câmbio real, reduz as exportações líquidas, inibindo a oferta de bens de investimento (bens de capital) que ocorre por meio de importações, num contexto de equilíbrio externo. Para que tal oferta não se reduza, torna-se necessário manter o nível das importações de bens de capital, apesar da queda das exportações líquidas, deteriorando-se o saldo em conta corrente.

Assim, supondo que déficits públicos implicam aumentos na absorção doméstica (ausência de crowding out e de Equivalência Ricardiana), a questão-chave é saber se o aumento da absorção doméstica resulta em apreciação da taxa de câmbio real, necessariamente. Tal apreciação levará a uma insuficiência de poupança nacional em relação a um dado nível de investimento ${ }^{10}$.

Portanto, é necessário avaliar os efeitos de déficits públicos sobre a taxa de câmbio real quando estes são financiados ou por emissão monetária ou pelo aumento da dívida pública interna, quer em regime de taxa de câmbio fixa, quer flexível, seja com o produto em seu nível de pleno emprego ou aquém deste e num modelo onde são contemplados os setores de BC e de BNC. Será feita a hipótese de ausência de crowding out e/ou Equivalência Ricardiana, a priori ${ }^{11}$. Por fim, como já deve estar claro, estamos no terreno do curto prazo, isto é, esta discussão não passa pelos (des)estímulos sobre a produção doméstica de bens de capital que o déficit público pode ensejar. Ademais, no médio/longo prazo a produção doméstica potencial de bens de investimento pode ser ampliada por meio do progresso técnico, não havendo o problema da falta de recursos reais para a viabilização do investimento - o que corresponderia à insuficiência de poupança nacional.

\footnotetext{
9 “A desvalorização aumenta o preço e reduz a demanda pelos bens chamados comerciáveis. Cai, portanto, o consumo desses bens e aumenta a poupança interna. Eis por que o saldo em conta corrente melhora." (Resende, 1995: 135).

${ }^{10}$ Krugman (1992), analisando os dados para a economia dos EUA, não encontrou evidencias de uma relação sistemática entre estas variáveis. Evans (1986) encontrou evidencias de que os déficits públicos norte americanos depreciam o dólar, ao invés de apreciá-lo. Estes resultados podem advir da ocorrência de crowding out e/ou Equivalência Ricardiana. De todo modo, antes da verificação empírica desta questão, deve-se proceder à sua análise teórica, tarefa executada neste trabalho.

${ }^{11}$ Conforme se verá adiante, o crowding out pode ocorrer, porém, não estamos assumindo de antemão que ele necessariamente se verificará.
} 


\section{Déficit público sob regime de taxa de câmbio fixa}

Economia operando a pleno emprego e déficit financiado por emissão de moeda

Suponha uma economia sob regime de taxa de câmbio fixa e operando a pleno emprego. Um aumento da demanda agregada decorrente de um déficit público financiado por meio de emissão monetária levará à apreciação da taxa de câmbio real. Ou seja, o excesso de demanda pressionará os preços nos setores de BC e BNC, e o ajuste se dará através do aumento de preços neste último e de importações de $\mathrm{BC}$, via mecanismos de arbitragem. A mudança de preços relativos em favor dos BNC resultará em apreciação da taxa de câmbio real e em deterioração do CC.

Esta situação pode ser representada graficamente segundo o modelo de Mundell-Fleming com preços flexíveis e perfeita mobilidade de capitais (Gráfico 1). Doravante, as representações gráficas de Mundell-Fleming trazem as seguintes hipóteses subjacentes: i) até o nível de produto de pleno emprego os preços são fixos, e, após este nível os preços são flexíveis; ii) há inicialmente equilíbrio no balanço de pagamentos.

O déficit público desloca a curva IS para a direita (IS'), enquanto a curva LM também se desloca para a direita (LM') em decorrência da emissão de moeda, conforme se constata no Gráfico 1 - a linha BP corresponde aos pares, renda e taxa de juros, que garantem o equilíbrio do balanço de pagamentos. Os deslocamentos de IS e de LM resultam, então, em aumento dos preços dos BNC e em aumento de importações financiadas através da entrada líquida de capitais. Os preços dos BC não se alteram (câmbio fixo). Assim, a taxa de câmbio real apreciase. O aumento de preços provoca a queda da oferta monetária real (M/P), deslocando LM' para sua posição inicial, enquanto IS' também retorna para sua posição inicial devido a apreciação da taxa de câmbio real.

Neste caso, partindo de uma situação de equilíbrio em CC, o déficit público, ao implicar aumento da absorção doméstica em relação ao produto nacional, resultou em queda da poupança nacional, operada por meio da apreciação da taxa de câmbio real. O conseqüente excesso do investimento sobre a poupança nacional será financiado através da absorção de poupança externa.

Este mesmo resultado seria obtido no contexto de imperfeita ou ausência de mobilidade de capitais. Apenas, a linha BP (inclinada ou vertical) também se deslocaria para a esquerda em função da apreciação da taxa de câmbio real, e o equilíbrio final seria alcançado em um ponto aquém do nível de pleno emprego.

Em suma, o déficit público financiado por meio de emissão de moeda implica a expansão da demanda agregada. Como conseqüência, o excesso de demanda pressiona os preços nos setores de $\mathrm{BC}$ e $\mathrm{BNC}$, e o ajuste se dá através do aumento de preços neste último e de importações de $\mathrm{BC}$, via mecanismos de arbitragem. A mudança de preços relativos em favor dos BNC resulta em apreciação da taxa de câmbio real e em deterioração do CC. 
Gráfico 1

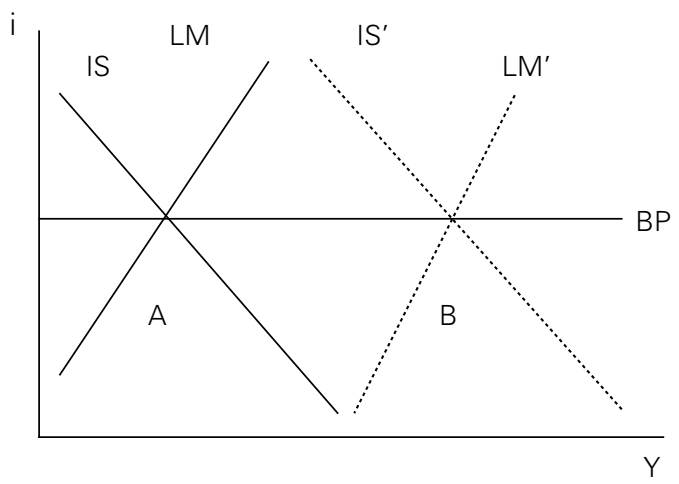

Economia operando aquém do pleno emprego

e déficit financiado por emissão de moeda

$\mathrm{Na}$ situação onde o nível do produto de equilíbrio está aquém do nível de pleno emprego, um aumento da absorção doméstica decorrente do déficit público pode resultar apenas na ampliação da produção interna de BC e de BNC. Neste caso, não há uma relação sistemática entre déficit público e apreciação da taxa de câmbio real. No modelo Mundell-Fleming com plena mobilidade de capitais o equilíbrio final, que corresponde ao ponto de encontro entre IS', LM' e BP do Gráfico 1 (ponto B), pode ser alcançado sem haver mudança de preços relativos.

Se a mobilidade de capitais for pequena, a linha BP torna-se positivamente inclinada e o ponto $\mathrm{B}$ estaria à sua direita, implicando déficit externo. A perda de reservas externas levaria ao enxugamento da base monetária e ao deslocamento para a esquerda da LM' até que esta curva cruzasse a linha BP, à direita do nível da renda inicial.

O resultado final, quer com plena mobilidade de capitais, quer com imperfeita mobilidade destes, seria um produto de equilíbrio maior e um déficit em conta corrente financiado pela entrada líquida de capitais. Porém, não teria se verificado, necessariamente, apreciação da taxa de câmbio real, e, portanto, redução da poupança nacional - redução da oferta de bens de investimento. Apenas as importações teriam crescido em função do aumento da renda ${ }^{12}$.

Se a mobilidade de capitais fosse nula, quando a economia alcançasse o ponto B a perda de reservas externas decorrente do aumento das importações provocaria o deslocamento da LM' para a esquerda até que o nível da renda inicial fosse restabelecido. Também neste caso não haveria mudança de preços relativos, necessariamente.

Em suma, na situação acima analisada, embora o déficit público estimule a

${ }^{12}$ Voltaremos a este ponto. 
demanda agregada, quando há (elevado nível de) capacidade ociosa na economia o resultado final deste processo onde os preços relativos não se alteram é um cenário factível. Neste caso, não se pode afirmar que o déficit público sempre provoca um déficit externo, isto é, não há uma relação de causalidade sistemática entre déficit público e déficit externo.

Economia operando a pleno emprego e déficit financiado por emissão de dívida pública interna

Num regime de taxas de câmbio fixas, quando o déficit público é financiado por meio do endividamento público numa economia que opera a pleno emprego, as taxas de juros reais domésticas podem se elevar. No contexto de plena (elevada) mobilidade de capitais isto provoca o influxo de capitais externos e, conseqüentemente, apreciação da taxa de câmbio real ${ }^{13}$.

No modelo Mundell-Fleming com plena mobilidade de capitais o déficit orçamentário implica o deslocamento da curva IS para a direita, elevando a taxa de juros real doméstica e atraindo capitais externos. Superávits no balanço de pagamentos levam à ampliação da base monetária e ao deslocamento para a direita da curva LM. A conseqüente elevação da renda estimula as importações e pressiona os preços dos BNC, apreciando a taxa de câmbio real. Este caso corrobora a tese dos déficits gêmeos, pois, através da apreciação da taxa de câmbio real o déficit público resulta em insuficiência de poupança nacional para um dado nível de investimento. $\mathrm{O}$ Gráfico 1 também representa esta situação. $\mathrm{O}$ ajuste que se segue à apreciação cambial implica um equilíbrio final no ponto A.

Se a mobilidade de capitais for imperfeita, a linha BP será positivamente inclinada e, após o deslocamento da IS para a direita, a renda terá crescido acima do seu nível inicial (de pleno emprego). Neste ponto há déficit no balanço de pagamentos e pressão altista sobre os preços de BNC. Assim, a taxa de câmbio real será apreciada e as curvas IS' e BP se deslocarão para a esquerda, em direção a IS" e BP'. A perda de reservas externas e o aumento de preços levarão ao deslocamento da LM para a esquerda até o ponto de encontro entre IS", BP' e LM' (ponto C do Gráfico 2). Neste caso, o déficit público resultou em apreciação da taxa de câmbio real.

Se a mobilidade de capitais for nula, após o deslocamento inicial da IS haverá déficit no balanço de pagamentos e aumento dos preços dos BNC, provocando apreciação da taxa de câmbio real e o deslocamento para a esquerda da IS', da LM e da BP. A LM se deslocará para a esquerda até que seja restabelecido o novo nível de equilíbrio da renda concomitantemente ao equilíbrio no balanço de pagamentos. Também aqui o déficit público resultou em apreciação da taxa de câmbio real.

${ }^{13}$ Este argumento está desenvolvido em Rosensweig \& Tallman (1993: 582). 


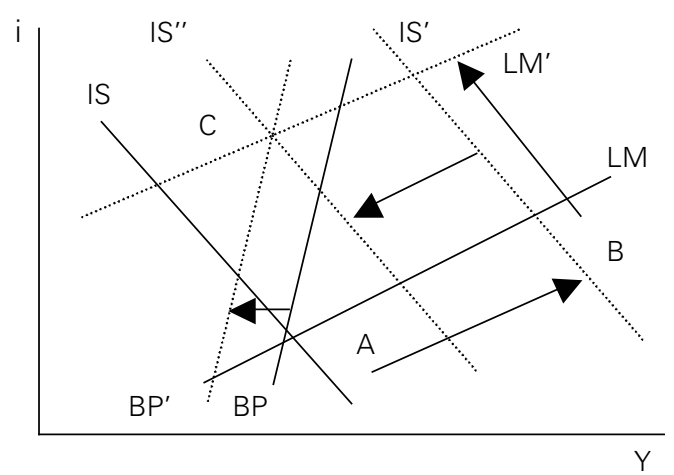

Em suma, na situação acima analisada, independentemente do grau de mobilidade de capitais, o financiamento do déficit orçamentário por meio do endividamento público pressiona a demanda agregada. Isto provoca apreciação da taxa de câmbio real por meio do aumento dos preços dos BNC, enquanto a taxa de câmbio nominal e os preços dos BC permanecem constantes. Portanto, através da apreciação da taxa de câmbio real o déficit público resulta em déficit externo.

Economia operando aquém do pleno emprego e déficit financiado por emissão de dívida pública interna

Quando o nível do produto de equilíbrio está aquém do nível de pleno emprego, o déficit público financiado por meio do endividamento público não provoca necessariamente a apreciação da taxa de câmbio real. O aumento da demanda por BNC pode resultar no aumento da sua produção doméstica, ao invés de provocar uma mudança de preços relativos. No modelo Mundell-Fleming com plena mobilidade de capitais o deslocamento para a direita da IS implicará aumento da taxa de juros doméstica e atração de capitais. Assim, a LM também se deslocará para a direita e o equilíbrio final corresponde ao ponto de encontro de IS', LM' e BP do Gráfico 1 (ponto B).

Se houver imperfeita mobilidade de capitais, a linha BP será positivamente inclinada e, após o deslocamento da IS para a direita, a LM se deslocará para a esquerda até o ponto de encontro entre IS', BP e LM'. A renda de equilíbrio terá crescido, embora possa ainda permanecer aquém do seu nível de pleno emprego. Neste caso, não há nenhuma pressão para a mudança dos preços relativos.

Se a mobilidade de capitais for nula, após o deslocamento da IS para a direita, o déficit externo implicará em perda de reservas e deslocamento da LM para a esquerda até que a renda inicial de equilíbrio, como também o equilíbrio em conta corrente, sejam restabelecidos, sem provocar apreciação da taxa de câmbio real.

No modelo IS/LM/BP o aumento da renda implica aumento das importações. Porém, deixando de lado este modelo, se inicialmente a balança comercial encon- 
trava-se equilibrada, tal aumento da renda não provoca necessariamente déficit comercial e em conta corrente - e, se não há déficit em conta corrente, não há redução da poupança nacional -, pois: i) quando há capacidade ociosa na economia num contexto de retornos crescentes de escala, o aumento da absorção doméstica estimulará o aumento do produto doméstico e a competitividade das exportações, a la Dixon \& Thirlwall (1994), o que pode resultar em equilíbrio da conta corrente; ii) o equilíbrio em conta corrente pode ser garantido se paralelamente ao crescimento das importações há incrementos das exportações em função de uma aceleração do crescimento da renda mundial; e, iii) no modelo IS/LM/BP as exportações são consideradas exógenas em relação à renda doméstica, porém esta simplificação não tem amparo no mundo real. Há na literatura nacional e internacional estimações de equações de exportação que demonstram a importância do grau de utilização da capacidade instalada, da renda real e da renda potencial, além da taxa de câmbio real, para explicar as exportações de um país ${ }^{14}$. Assim, quando a renda se eleva as exportações também podem aumentar. Portanto, não há, no caso em análise, uma relação sistemática entre déficit público e déficit externo.

Em suma, na situação acima analisada, quando há (elevado nível de) capacidade ociosa na economia o déficit público não provoca necessariamente apreciação da taxa de câmbio real. Ademais, é possível que as importações cresçam pari passu às exportações, implicando equilíbrio em conta corrente. Neste caso, não há uma relação de causalidade sistemática entre déficit público e déficit externo.

\section{Déficit público sob regime de taxas de câmbio flexíveis}

Economia operando a pleno emprego e déficit financiado por emissão de moeda

Numa economia sob regime de taxas de câmbio flexíveis e operando a pleno emprego, um déficit público financiado por emissão monetária pressionará os preços dos BC e dos BNC. A taxa de câmbio nominal acompanhará o aumento de preços, mantendo-se o equilíbrio externo, ceteris paribus. A inflação resultante acomodará o aumento da absorção pública por meio da redução da absorção privada, em termos reais. Após o ajuste via preços, não surgirá necessariamente uma alteração na taxa de câmbio real.

Esta situação pode ser representada graficamente segundo o modelo de Mundell-Fleming com ausência de mobilidade de capitais (Gráfico 3). O déficit público implica um deslocamento para a direita da curva IS, enquanto a emissão de moeda desloca a curva LM para a direita, até LM'. O excesso da absorção em relação ao nível do produto de pleno emprego pressiona para cima os preços dos BNC e dos BC. No regime de câmbio flexível, o aumento dos preços dos BC estimula a demanda de importação, porém esta não cresce, pois a taxa de câmbio nominal

\footnotetext{
${ }^{14}$ Ver, por exemplo, Goldstein \& Khan (1985) e Castro \& Cavalcanti (1998).
} 
também se eleva (vale a Lei do Preço Único). É possível, então, que não ocorra mudança de preços relativos. Neste caso, IS' e BP não se deslocam, porém a inflação reduz a oferta monetária real e a curva LM' desloca-se para a esquerda. Este processo só se estabiliza no ponto de encontro da LM" com a IS' e com a BP (ponto C do Gráfico 3), onde o nível do produto é o de pleno emprego.

Com plena mobilidade de capitais, o déficit público financiado com emissão monetária num contexto de pleno emprego resultará em apreciação da taxa de câmbio real. No ponto B do Gráfico 3 (com a linha BP horizontal), há uma pressão altista sobre os preços dos BNC e dos BC. Porém, enquanto aqueles aumentam, estes últimos não se elevam, pois haverá sempre suficiente oferta de divisas externas para financiar as importações. Assim, verificar-se-á uma mudança de preços relativos. A IS' e a LM' se deslocarão para a esquerda até o equilíbrio final no ponto $\mathrm{A}$, onde o nível do produto é o de pleno emprego.

Quando a mobilidade de capitais é pequena, o ponto B do Gráfico 3 estará à direita da linha BP inclinada. Há uma pressão altista sobre os preços dos BNC e dos BC. A oferta monetária real se retrai e a LM desloca-se para a esquerda, provocando um aumento da taxa de juros doméstica. Porém, a entrada líquida de capitais permite a ocorrência de um ponto de encontro entre IS, LM e BP (inclinada) que corresponde a um nível de renda superior ao de pleno emprego. Assim haverá pressão altista sobre os preços dos $\mathrm{BNC}$ superior àquela verificada sobre os preços dos BC, já que pelo menos uma parcela desta pressão no setor de BC será desviada para importações financiadas pela entrada líquida de capitais no balanço de pagamentos. Haverá, então, apreciação da taxa de câmbio real. A partir daí, novo ajuste ocorrerá por meio do deslocamento para a esquerda de IS', LM' e BP.

\section{Gráfico 3}

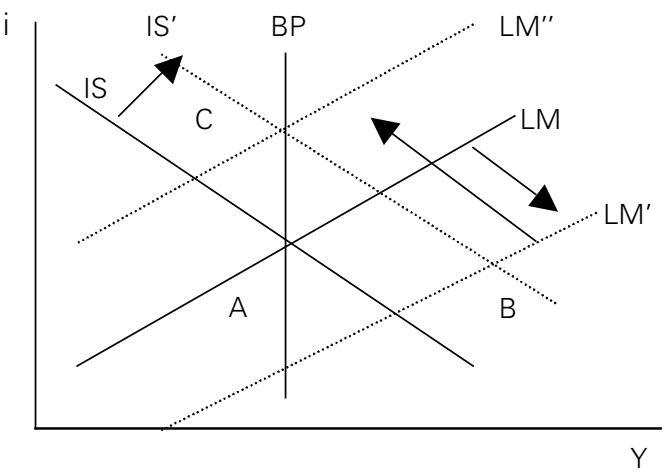

Em suma, se a economia opera com taxas de câmbio flexíveis e com o produto no seu nível de pleno emprego, o aumento da demanda agregada decorrente do déficit público pressionará para cima tanto os preços de $\mathrm{BNC}$ como os preços dos $\mathrm{BC}$ - neste último caso o aumento de preços acompanha a elevação da taxa de câmbio nominal. Quanto menor for a mobilidade de capitais, menor será a dife- 
rença de aumento de preços de BC e de BNC. Assim, quando a mobilidade de capitais é nula não há mudança de preços relativos ao final do processo de ajustamento. Neste caso, o déficit público não implica déficit em conta corrente.

Economia operando aquém do pleno emprego

e déficit financiado por emissão de moeda

Com um nível de produto aquém do seu nível de pleno emprego, um déficit público financiado por emissão monetária pode estimular o aumento da produção de BC e de BNC sem provocar necessariamente uma mudança de preços relativos. Neste caso, chega-se à mesma conclusão: não há uma relação sistemática entre déficit público e insuficiência de poupança nacional em relação a um dado nível de investimento.

No modelo de Mundell-Fleming com ausência de mobilidade de capitais, há inicialmente um deslocamento da IS e da LM para a direita. O equilíbrio final corresponde ao ponto de interseção de IS" com LM' e BP', ponto C do Gráfico 4. As curvas IS' e BP se deslocam para a direita até o ponto $\mathrm{C}$ visto que o aumento da renda, possível quando há capacidade ociosa nos setores de BNC e de BC, implica aumento da demanda por importações e, portanto, depreciação das taxas de câmbio nominal e real ${ }^{15}$.

Com pequena (finita) mobilidade de capitais ter-se-ia o mesmo resultado apresentado no Gráfico 4, apenas as linhas BP e BP' seriam positivamente inclinadas ${ }^{16}$. Ou seja, neste último caso também não haveria apreciação da taxa de câmbio real propiciada pela ocorrência de déficit público. Este mesmo resultado obterse-ia com plena mobilidade de capitais - apenas não haveria depreciação das taxas de câmbio nominal e real, e o equilíbrio final seria no ponto B por onde passaria uma linha BP horizontal (Gráfico 4).

\footnotetext{
${ }^{15}$ Conforme considerado anteriormente, até o nível de produto de pleno emprego os preços são fixos, e, após este nível, eles são flexíveis. Todavia, se houver elevação da taxa de câmbio nominal haverá aumento de preços dos $\mathrm{BC}$, mesmo estando este setor com um nível inicial de produto aquém do nível de pleno emprego. Isto ocorre, pois, devido à arbitragem no mercado internacional, a elevação da taxa de câmbio provocaria forte demanda externa pelos BC e o pleno emprego nesse setor seria rapidamente alcançado, pressionando seus preços (Lei do Preço Único). Note que, com a depreciação cambial, a linha BP desloca-se mais do que a renda de equilíbrio. Sobre este ponto, ver Carvalho et al. (2001: 438).

${ }^{16}$ De acordo com o que foi destacado anteriormente, desfazendo-se da limitação do modelo de Mundell-Fleming relacionada à hipótese de exogeneidade das exportações, o crescimento destas pode estar associado ao crescimento da renda, conforme se verifica sob hipótese de retornos crescentes de escala. Neste caso, o aumento do produto doméstico estimulará a competitividade das exportações, à la Dixon \& Thirlwall (1994), e o equilíbrio comercial será mantido. Assim, não haveria depreciação da taxa de câmbio real. Apenas, a linha BP também se deslocaria para a direita. Neste caso, esse resultado de ausência de apreciação da taxa de câmbio real, isto é, de ausência de desequilíbrio externo, poderia ser demonstrado seja para a situação onde a linha BP é inclinada (pequena mobilidade de capitais) ou horizontal (plena mobilidade de capitais).
} 


\section{Gráfico 4}

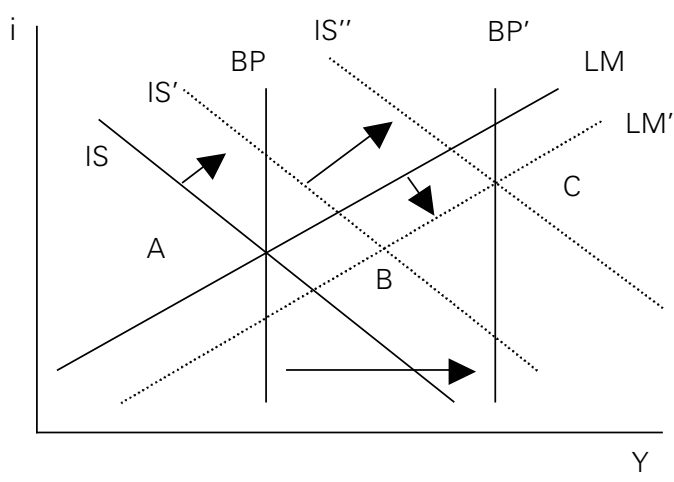

Em suma, na situação acima analisada, o aumento da demanda agregada, decorrente do déficit público, implica crescimento da demanda por divisas para importar e, conseqüentemente, depreciação da taxa de câmbio nominal e real quando o grau de mobilidade de capitais não é infinito. Portanto, neste caso não se verifica uma relação de causalidade entre déficit público e déficit externo. Se a mobilidade de capitais é plena, então o aumento da demanda de divisas para importar seria contrabalançado pelo aumento da oferta das mesmas, e a taxa de câmbio real não se depreciaria e nem se apreciaria.

Economia operando a pleno emprego e déficit financiado por emissão de dívida pública interna

Numa economia sob regime de taxas de câmbio flexíveis e que opera a pleno emprego, os déficits do governo financiados por meio do endividamento público representam queda da poupança pública, que, por hipótese, não é compensada pelo aumento da poupança privada. Assim, a poupança nacional se reduz em relação ao investimento agregado provocando elevação da taxa de juros real doméstica, aumentando a oferta líquida de divisas externas - supondo que a mobilidade de capitais é suficiente para que a entrada destes mais do que compense o aumento da demanda de divisas externas, associado à elevação do déficit públi$\mathrm{Co}^{17}$. Assim, as taxas de câmbio nominal e real apreciam-se (Feldstein, 1992: 2-3; Rosensweig \& Tallman, 1993: 582; Krugman, 1992: 5).

\footnotetext{
${ }^{17}$ No pleno emprego, o déficit público pressiona a absorção nos setores de BC e BNC. Neste último, verificar-se-á uma elevação de preços. No primeiro setor, o aumento da absorção pressionará a taxa de câmbio nominal para cima se a atração de capitais promovida pelo aumento das taxas de juros domésticas não for suficientemente elevada. Neste caso, a elevação da taxa de câmbio nominal estimula o aumento de preços também no setor de BC. Porém se há alguma (imperfeita) mobilidade de capitais, a
} 
Porém, se a mobilidade de capitais for nula não haverá apreciação da taxa de câmbio real, e o déficit público resultará apenas em inflação em ambos os setores de BC e de BNC. No modelo Mundell-Fleming, este resultado pode ser representado pelo Gráfico 3, desde que a curva LM' seja eliminada (o governo reduziu a base monetária ao vender títulos e a expandiu na mesma magnitude ao usar os recursos obtidos com a operação de mercado aberto para financiar seu déficit). A inflação provoca o deslocamento da LM para a esquerda. O equilíbrio final se dará no ponto $\mathrm{C}$ do Gráfico 3.

Em suma, a expansão da demanda agregada (que decorre do déficit orçamentário do governo financiado através da ampliação da dívida pública) paralelamente à ausência de mobilidade de capitais implica crescimento dos preços dos $\mathrm{BNC} e$ dos BC na mesma proporção. Apenas no caso dos BC há um aumento de preços no contexto da Lei do Preço Único, isto é, o excesso de demanda neste setor implica aumentos conjuntos da taxa de câmbio nominal e dos preços dos BC. Portanto, não há neste caso mudança de preços relativos ao final do processo, permitindo a rejeição da hipótese de relação de causalidade entre déficit público e apreciação da taxa de câmbio real. Resultado distinto deste é obtido quando há plena mobilidade de capitais.

Economia operando aquém do pleno emprego

e déficit financiado por emissão de dívida pública interna

Sob taxas de câmbio flexíveis, havendo capacidade ociosa na economia o déficit público financiado por emissão de dívida interna não leva à apreciação da taxa de câmbio real, necessariamente. No modelo Mundell-Fleming este resultado está representado no Gráfico 5, onde há ausência de mobilidade de capitais. Inicialmente a curva IS desloca-se para a direita, estimulando a produção de BC e de BNC. O decorrente aumento da renda estimula a demanda por importações, e a taxa de câmbio nominal e os preços dos BC elevam-se. A taxa de câmbio real deprecia-se e as curvas IS' e BP deslocam-se para a direita. O novo ponto de equilíbrio é o ponto C.

Com pequena (finita) mobilidade de capitais obter-se-ia o mesmo resultado apresentado no Gráfico 5, apenas as linhas BP e BP' seriam positivamente inclinadas ${ }^{18}$. Ou seja, neste último caso também não haveria apreciação da taxa de câmbio real propiciada pela ocorrência de déficits públicos.

entrada de divisas externas impede que a taxa de câmbio nominal e que os preços dos BC subam na mesma proporção dos preços dos BNC, implicando apreciação da taxa de câmbio real.

${ }^{18}$ Ver nota de rodapé 16. 


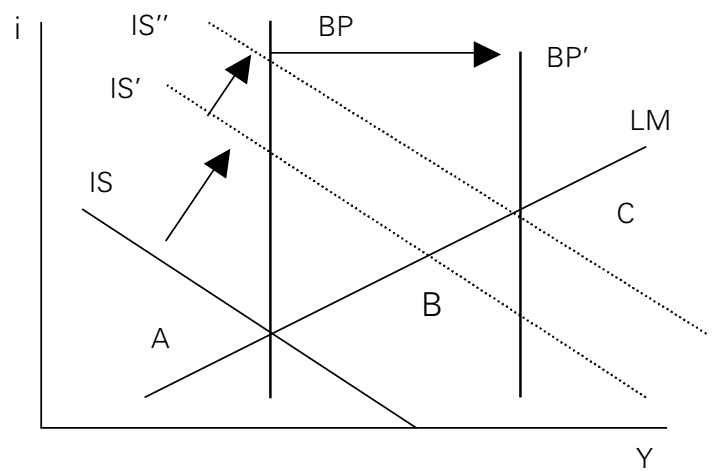

Se a mobilidade de capitais for plena, o deslocamento inicial da IS será revertido em função da apreciação da taxa de câmbio nominal, e real, provocada pela forte entrada de capitais no balanço de pagamentos. Neste caso, o déficit púbico, ao proporcionar aumentos na taxa de juros doméstica, atraindo capitais externos, provocaria apreciação da taxa de câmbio real, reduzindo a poupança nacional.

Em suma, na situação acima analisada, apenas quando a mobilidade de capitais é infinita (ou muito elevada) o déficit público causaria apreciação da taxa de câmbio real. Caso contrário, a expansão da demanda agregada, decorrente do déficit do governo, não levaria a aumentos de preços de BNC, pois há capacidade ociosa na economia, enquanto o crescimento da renda e da demanda por importações levaria à depreciação da taxa de câmbio nominal e real.

\section{Síntese dos Resultados}

Os Quadros 1 e 2 sintetizam os efeitos do déficit público sobre os preços relativos segundo os casos analisados sob os regimes de taxa de câmbio fixa e flexível. A análise destes casos foi realizada sob a hipótese de ausência de crowding out e de Equivalência Ricardiana.

Sob o regime de taxa de câmbio fixa, quando o produto está aquém do seu nível de pleno emprego, não se constatou uma relação de causalidade sistemática entre déficit público e apreciação da taxa de câmbio real, independentemente do grau de mobilidade de capitais ou da forma de financiamento do déficit. Quando o produto se encontra no seu nível de pleno emprego, o déficit público provoca apreciação da taxa de câmbio real, independentemente do grau de mobilidade de capitais ou da forma de financiamento. 
Quadro 1

Relação entre Déficit Público e Apreciação da Taxa de Câmbio Real - Taxa de Câmbio Fixa

\begin{tabular}{|c|c|c|c|}
\hline & & Emissão Monetária & $\begin{array}{l}\text { Emissão de Dívida } \\
\text { Pública }\end{array}$ \\
\hline \multirow{2}{*}{ Pleno Emprego } & $\begin{array}{l}\text { Plena Mobilidade } \\
\text { de Capitais }\end{array}$ & $\begin{array}{l}\text { Apreciação da taxa } \\
\text { de câmbio real }\end{array}$ & $\begin{array}{l}\text { Apreciação da taxa } \\
\text { de câmbio real }\end{array}$ \\
\hline & $\begin{array}{c}\text { Nula Mobilidade de } \\
\text { Capitais }\end{array}$ & $\begin{array}{l}\text { Apreciação da taxa } \\
\text { de câmbio real }\end{array}$ & $\begin{array}{l}\text { Apreciação da taxa } \\
\text { de câmbio real }\end{array}$ \\
\hline \multirow{2}{*}{$\begin{array}{l}\text { Aquém do } \\
\text { Pleno Emprego }\end{array}$} & $\begin{array}{l}\text { Plena Mobilidade } \\
\text { de Capitais }\end{array}$ & $\begin{array}{l}\text { Não há apreciação da } \\
\text { taxa de câmbio real }\end{array}$ & $\begin{array}{l}\text { Não há apreciação da } \\
\text { taxa de câmbio real }\end{array}$ \\
\hline & $\begin{array}{l}\text { Nula Mobilidade de } \\
\text { Capitais }\end{array}$ & $\begin{array}{l}\text { Não há apreciação da } \\
\text { taxa de câmbio real }\end{array}$ & $\begin{array}{l}\text { Não há apreciação da } \\
\text { taxa de câmbio real }\end{array}$ \\
\hline
\end{tabular}

Fonte: Elaboração própria.

Sob o regime de taxa de câmbio flexível, quando o produto está aquém do seu nível de pleno emprego, não se constatou uma relação de causalidade sistemática entre déficit público e apreciação da taxa de câmbio real, exceto quando a mobilidade de capitais é plena (elevada) e o déficit é financiado através de emissão de dívida pública. Neste último caso, quanto menos perfeita for a mobilidade de capitais, tanto menor será o impacto do déficit público sobre a mudança de preços relativos e sobre o déficit externo. Em termos do modelo Mundell-Fleming, o déficit público só provoca apreciação da taxa de câmbio real quando a linha LM apresentar uma inclinação maior do que a linha BP.

Quando o produto se encontra no seu nível de pleno emprego e o regime cambial é o de taxa flexível, o déficit público provoca apreciação da taxa de câmbio real no contexto de plena mobilidade de capitais.

Quadro 2

Relação entre Déficit Público e Apreciação da Taxa de Câmbio Real - Taxa de Câmbio Flexível

\begin{tabular}{|c|c|c|c|}
\hline & & Emissão Monetária & $\begin{array}{l}\text { Emissão de Dívida } \\
\text { Pública }\end{array}$ \\
\hline \multirow{2}{*}{ Pleno Emprego } & $\begin{array}{l}\text { Plena Mobilidade de } \\
\text { Capitais }\end{array}$ & $\begin{array}{c}\text { Apreciação da taxa de } \\
\text { câmbio real }\end{array}$ & $\begin{array}{l}\text { Apreciação da taxa } \\
\text { de câmbio real }\end{array}$ \\
\hline & $\begin{array}{l}\text { Nula Mobilidade de } \\
\text { Capitais }\end{array}$ & $\begin{array}{l}\text { Não há apreciação da } \\
\text { taxa de câmbio real }\end{array}$ & $\begin{array}{l}\text { Não há apreciação da } \\
\text { taxa de câmbio real }\end{array}$ \\
\hline \multirow{2}{*}{$\begin{array}{l}\text { Aquém do } \\
\text { Pleno Emprego }\end{array}$} & $\begin{array}{l}\text { Plena Mobilidade de } \\
\text { Capitais }\end{array}$ & $\begin{array}{l}\text { Não há apreciação da } \\
\text { taxa de câmbio real }\end{array}$ & $\begin{array}{l}\text { Apreciação da taxa } \\
\text { de câmbio real }\end{array}$ \\
\hline & $\begin{array}{l}\text { Nula Mobilidade de } \\
\text { Capitais }\end{array}$ & $\begin{array}{l}\text { Não há apreciação da } \\
\text { taxa de câmbio real }\end{array}$ & $\begin{array}{l}\text { Não há apreciação da } \\
\text { taxa de câmbio real }\end{array}$ \\
\hline
\end{tabular}

Fonte: Elaboração própria.

Deste modo, mesmo supondo ausência de crowding out e de Equivalência Ricardiana, a tese dos déficits gêmeos só se sustenta mediante a hipótese de pleno 
emprego dos fatores quando o regime cambial é o de taxas fixas. No caso do regime cambial de taxas flexíveis há duas situações em que não se pode rejeitar a tese dos déficits gêmeos: i) quando a economia opera aquém do pleno emprego e, paralelamente, há plena (ou elevada) mobilidade de capitais e o déficit é financiado por meio da emissão de dívida pública; ii) quando as hipóteses de pleno emprego e de plena mobilidade de capitais são satisfeitas conjuntamente.

Portanto, exceto no caso do item (i) acima, quer no âmbito de taxas de câmbio fixas, quer no contexto de taxas de câmbio flexíveis, o déficit público causa apreciação da taxa de câmbio real apenas se a economia opera a pleno emprego dos fatores. Todavia, a situação de pleno emprego seria apenas uma entre inúmeras possibilidades de equilíbrio macroeconômico (Keynes, 1988). O pleno emprego seria um caso especial do caso geral.

\section{CONCLUSÕES}

O estudo da relação entre déficit público, insuficiência de poupança nacional e déficit em conta corrente requer o conhecimento dos mecanismos (ou incentivos) através dos quais o déficit público poderia reduzir a poupança nacional e estimular o déficit externo. Tais mecanismos (incentivos) não podem ser demonstrados por meio de identidades contábeis, pois estas não apresentam relações de causalidade.

$\mathrm{Na}$ economia fechada, dada a renda agregada, o déficit público não reduz a poupança nacional. Isto ocorre por que bens de capital que produzem bens de capital não podem se metamorfosear em máquinas produtoras de bens de consumo para atender às demandas de um governo perdulário. Todavia, na economia aberta, uma apreciação da taxa de câmbio real pode ser conseqüência do déficit público, redundando em queda da poupança nacional e em déficit em conta corrente. Portanto, a mudança de preços relativos é o mecanismo por meio do qual o déficit público causa insuficiência de poupança nacional em relação a uma dada taxa de investimento.

Avaliou-se, neste artigo, se é verdadeira a hipótese de que o déficit público sempre causa um déficit em conta corrente (tese dos déficits gêmeos). Tal hipótese foi analisada a partir do estudo teórico da relação de causalidade entre déficit público e apreciação da taxa de câmbio real, em diversos contextos. Embora este estudo não pretendesse esgotar todos os casos possíveis, a verificação de um único caso em que o déficit público não provocasse a apreciação da taxa de câmbio real seria suficiente para se rejeitar a hipótese citada.

Demonstrou-se na segunda seção que em vários casos estudados o déficit público não causa apreciação da taxa de câmbio real. Portanto, não há uma relação de causalidade sistemática entre déficit público e apreciação da taxa de câmbio real. No regime de taxa de câmbio fixa, tal relação é válida apenas quando a economia opera a pleno emprego concomitantemente à ausência de Equivalência Ricardiana e de crowding out. No regime de taxa de câmbio flexível esta relação é 
válida apenas em duas situações: i) quando a economia opera a pleno emprego e, ainda, há infinita (ou elevada) mobilidade de capitais e ausência de Equivalência Ricardiana e de crowding out; ou, ii) quando a economia opera aquém do pleno emprego e, paralelamente, há plena (ou elevada) mobilidade de capitais, o déficit é financiado por meio da emissão de dívida pública e há ausência de Equivalência Ricardiana e de crowding out.

Portanto, se é através da apreciação da taxa de câmbio real que déficits públicos resultam em insuficiência da poupança nacional, a tese de que déficits públicos implicam deterioração do saldo em conta corrente e a necessidade de absorção de poupança externa visando garantir o financiamento de uma dada taxa de investimento não parece ter consistência teórica. Tal tese fica ainda mais fragilizada quando se considera a possibilidade de ocorrência de crowding out e/ou Equivalência Ricardiana. Por simetria, pode-se afirmar que o superávit público não provoca, necessariamente, a depreciação da taxa de câmbio real. Portanto, o ajuste fiscal público não leva, necessariamente, à ampliação da oferta de bens de investimento - ampliação da poupança nacional.

\section{REFERÊNCIAS BIBLIOGRÁFICAS}

AMADEO, E.J. Nem câmbio nem ajuste fiscal. Revista de Economia Política, vol 15, n. 2, (58), abril-junho, 1995.

BAHARUMSHAH, A.Z.; LAU, E.; KHALID, A.M. Testing Twin Deficits Hypothesis: Using VAR`s and Variance Decomposition. Economics Working Paper Archive at WUSTL, 2005.

CARVALHO, F.J.C.; SOUZA, F.E.P.; SICSÚ, J.; PAULA, L.F.R. \& STUDART, R. Economia monetária e financeira: teoria e política. Rio de Janeiro, ed.Campus, 2001.

CASTRO, A.S. \& CAVALCANTI, M.A.F.H., Estimação de equações de exportação e importação para o Brasil - 1955/95. Pesquisa e Planejamento Econômico, v. 28, n. 1, abril de 1998.

DIXON R. \& THIRLWALL, A.P. A model of regional growth-rate differences on Kaldorian lines. In King, J.E. Economic growth in theory and practice: a Kaldorian perspective. Cambridge, Edward Elgar, 1994.

EVANS, P. Is the Dollar high because of large budget deficits? Journal of Monetary Economics, November, 1986.

FEIJÓ, C.A.; RAMOS, R.L.O.; YOUNG, C.E.F.; LIMA, F.G.C. \& GALVÃO, O.J.A. Contabilidade social: o novo sistema de Contas Nacionais do Brasil. Rio de Janeiro, Campus, 2001.

FELDSTEIN, M. The budget and trade déficits aren't really twins. Cambridge, NBER, Working Paper $n$. 3966, janeiro de 1992.

FELDSTEIN, M. \& HORIOKA, C. Domestic saving and international capital flows. The Economic Journal, 90, junho de 1980 .

GARCIA, M.G.P. Macroeconomia prática. Gazeta Mercantil, pg. A-3, 16 de abril de 1997.

GIAMBIAGI, F. \& AMADEO, E.J. Taxa de poupança e política econômica: notas sobre as possibilidades de crescimento numa economia com restrições. Revista de Economia Política, v. 10, n. 1(37), janeiromarço de 1990.

GOLDSTEIN, M. \& KHAN, Income and price effects in foreign trade. In Handbook of International Economics, Jones \& Kenen, V.2, Amsterdan, Elsevier Publishers, 1985.

KANDIR, A. A dinâmica da inflação: uma análise das relações entre inflação, fragilidade financeira do setor público, expectativas e margens de lucro. São Paulo, ed. Nobel, 1989.

KEYNES, J.M. A teoria geral do emprego, do juro e da moeda. São Paulo, Nova Cultural, 1988.

KRUGMAN, P.R. Currencies and Crises. Cambridge, MIT Press, 1992. 
LABINI, S.P. Oligopoly and techinical progress. Cambridge, Harvard University Press, 1962.

OSKOOEE, M.B. The long-run determinants of U.S. trade balance revisited. Journal of Post Keynesian Economics, vol. 17, n. 3, 1995.

PASTORE, A.C. \& PINOTTI, M. C. Taxa cambial real e os saldos comerciais. Revista de Economia Política, vol 15, n. 2, (58), abril-junho, 1995.

PEREIRA, T.R. Endividamento externo e o ajuste financeiro da grande empresa industrial nos anos noventa. Campinas, Dissertação de mestrado/Instituto de Economia da Unicamp, 1999.

RESENDE, A.L. O México e o câmbio: tequila, câmbio e o velho cinismo. Revista de Economia Política, vol 15, n. 2, (58), abril-junho 1995.

RESENDE, M.F.C. Inserção internacional, arranjos financeiros e crescimento da economia brasileira. Tese de Doutorado/Departamento de Economia da UnB, 2003.

ROSENSWEIG, J.A. \& TALLMAN, E.W. Fiscal policy and trade adjustment: are the deficits really twins? Economic Inquiry, vol. XXXI, October, 1993.

SIMONSEN, M.H. \& CYSNE, R.P. Macroeconomia. Rio de Janeiro, Fundação Getúlio Vargas, 2a edição, 1995.

STUDART, R. Investment finance in economic development. London, Routledge, 1995.

TAVARES, M.C., ASSIS, J.C. \& TEIXEIRA, A. A questão da poupança: desfazendo confusões. In TAVARES, M.C. \& DAVID, M.D. (org.) A economia política da crise, Rio de Janeiros, ed. Vozes, 1982.

VAMVOUKAS, G.A. The twin deficits phenomenon: evidence from Greece. Applied Economics, 31, 1999. 